\title{
Alteration of transthyretin and thyroxine-binding globulin in major depressive disorder: multiple reaction monitoring-based proteomic analysis
}

\author{
Hye In $\mathrm{Woo}^{1 \dagger}$, Jisook Park ${ }^{2 \dagger}$, Shinn-Won Lim ${ }^{3}$, Doh Kwan Kim ${ }^{4 *}$ and Soo-Youn Lee $5,6^{*}$ (c)
}

\begin{abstract}
Background: Major depressive disorder (MDD), common mental disorder, lacks objective diagnostic and prognosis biomarkers. The objective of this study was to perform proteomic analysis to identify proteins with changed expression levels after antidepressant treatment and investigate differences in protein expression between MDD patients and healthy individuals.
\end{abstract}

Methods: A total of 111 proteins obtained from literature review were subjected to multiple reaction monitoring (MRM)-based protein quantitation. Finally, seven proteins were quantified for plasma specimens of 10 healthy controls and 78 MDD patients (those at baseline and at 6 weeks after antidepressant treatment of either selective serotonin reuptake inhibitors (SSRIs) or mirtazapine).

Results: Among 78 MDD patients, 35 patients were treated with SSRIs and 43 patients were treated with mirtazapine. Nineteen (54.3\%) and 16 (37.2\%) patients responded to SSRIs and mirtazapine, respectively. Comparing MDD patients with healthy individuals, alteration of transthyretin was observed in MDD $(P=0.026)$. A few differences were observed in protein levels related to SSRIs treatment, although they were not statistically significant. Plasma thyroxine-binding globulin (TBG) was different between before and after mirtazapine treatment only in responders $(P=0.007)$.

Conclusions: In proteomic analysis of plasma specimens from MDD patients, transthyretin and TBG levels were altered in MDD and changed after antidepressant treatment.

Keywords: MDD, Selective serotonin reuptake inhibitors, SSRI, Mirtazapine, Proteomics, Thyroid

*Correspondence: paulkim@skku.edu; suddenbz@skku.edu

${ }^{\dagger}$ Hye In Woo and Jisook Park contributed equally to this work

${ }^{4}$ Department of Psychiatry, Samsung Medical Center, Sungkyunkwan University School of Medicine, \#81 Irwon-ro, Gangnam-gu, Seoul 06351,

Korea

${ }^{5}$ Department of Laboratory Medicine and Genetics, Samsung Medical

Center, Sungkyunkwan University School of Medicine, \#81 Irwon-ro, Gangnam-gu, Seoul 06351, Korea

Full list of author information is available at the end of the article

\section{Background}

Major depressive disorder (MDD) is a psychiatric disorder with heterogeneous symptoms, including distinct change of mood, sadness, and psychophysiological changes sleep and appetite disturbances [1]. Globally, MDD affects approximately $5-20 \%$ of the world population $[2,3]$.

Many previous studies have reported that patients with MDD show various kinds of biological disturbance, including abnormal functioning of neurotransmitters [4], inflammatory changes [5], and dysregulation of the

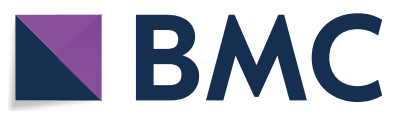

(c) The Author(s) 2021. This article is licensed under a Creative Commons Attribution 4.0 International License, which permits use, sharing, adaptation, distribution and reproduction in any medium or format, as long as you give appropriate credit to the original author(s) and the source, provide a link to the Creative Commons licence, and indicate if changes were made. The images or other third party material in this article are included in the article's Creative Commons licence, unless indicated otherwise in a credit line to the material. If material is not included in the article's Creative Commons licence and your intended use is not permitted by statutory regulation or exceeds the permitted use, you will need to obtain permission directly from the copyright holder. To view a copy of this licence, visit http://creativeco mmons.org/licenses/by/4.0/. The Creative Commons Public Domain Dedication waiver (http://creativecommons.org/publicdomain/ zero/1.0/) applies to the data made available in this article, unless otherwise stated in a credit line to the data. 
endocrine system that include a dysregulated hypothalamic-pituitary-adrenal axis $[6,7]$ and reproductive endocrine changes [8]. However, etiology and consequences of MDD remain unclear due to innate complexity of MDD and multifactored etiologies such as genetic and environmental factors including trauma during childhood or adulthood and stressful life events [9]. Currently there are no firm biomarkers for diagnosis of MDD [10], leading to the lack of objective diagnostic tool and misdiagnosis of MDD, especially in primary care setting [10]. Although at least one-third of patients treated with second-generation antidepressants do not achieve treatment responses $[11,12]$, there is no relevant biomarker to predict antidepressant treatment response either.

To identify biomarkers of MDD, many studies have been conducted in diverse research fields, including genomics, transcriptomics, proteomics, and metabolomics [13-16]. Especially, proteomic approach is considered a promising tool because proteins account environmental influence and closely reflect the pathophysiologic process of psychiatric conditions [17]. To discover diagnostic biomarkers for MDD using proteomic approach, several clinical studies have been performed using brain tissue $[18,19]$, cerebrospinal fluid (CSF) [20], urine [21], and serum/plasma [22-24]. These studies have reported protein expression alterations in lipid metabolism and immunoregulation [23, 25], inflammatory response [26], oxidative stress response, growth factor pathway [24], neuroprotection, and neuronal development [20] in MDD compared to healthy individuals.

A few proteomic studies related to prediction of treatment response and changes by antidepressant treatment have been reported, including increase of pigment epithelium-derived factor level after electroconvulsive therapy (ECT) [27], decrease of proteasome subunit $\alpha$ type-2 in antidepressant responders [28], and association of apolipoprotein A-IV with antidepressant response [29]. However, these studies are focused on changes of proteins according to mixed antidepressants $[28,29]$ and ECT [27], or on proteins involved in immune, endocrine, and metabolic processes [29]. More proteomic studies using precise analytic method to identify predictive protein markers, especially peripheral blood markers, are required because they are non-invasive and practical for clinical use [10].

Therefore, the objective of this study was to perform multiple reaction monitoring (MRM)-based proteomic analysis to identify proteins whose expression levels were changed after antidepressant treatment, that might be able to predict treatment response, and assess differences in protein expression between MDD patients and healthy individuals. We screened 111 proteins using MRM method and performed quantitative proteomic analysis usingstable isotope labeled peptide in plasma from MDD patients. To the best of our knowledge, this is the first report describing changes in protein levels after antidepressant treatment in MDD patients using MRM-based proteomic analysis.

\section{Methods \\ Patients}

MDD patients fulfilling the Diagnostic and Statistical Manual of Mental Disorders, Fourth Edition, criteria for major depressive episode who were treated with selective serotonin reuptake inhibitors (SSRIs: escitalopram, fluoxetine, paroxetine, sertraline), or non-SSRI (mirtazapine) were recruited. Diagnosis was confirmed by board certified psychiatrists based on Samsung Psychiatric Evaluation Schedule, case review notes, and SCID (structured clinical interview for DSM-IV) to diagnose depression. A minimum baseline score of 15 for 17-item Hamilton Rating Scale for Depression (HAM-D) was required [30]. Study participants were excluded if they had pregnancy, significant medical conditions, abnormal laboratory baseline values, unstable psychiatric features (e.g., suicidal), history of alcohol or drug dependence, seizures, head trauma with loss of consciousness, neurological illness, or concomitant Axis I psychiatric disorder.

Patients received monotherapy for 6 weeks with one of four commonly used SSRI or mirtazapine antidepressants by clinician's choice. In this study, choice of drug was driven by the preference of the physician, with consideration of anticipated side effects in at-risk individuals. Dose titration was completed within two weeks. Trough plasma samples were drawn at the end of week 6 for plasma drug concentrations. Lorazepam $0.5-1 \mathrm{mg}$ was allowed at bedtime for insomnia. Patients were seen by a psychiatrist, who monitored their adverse events and severity of depression. The HAM-D was administered by a single trained rater every two weeks [30]. The rater and personnel of protein quantitation were blinded to the hypotheses, drug assignment, and HAM-D data. Therapeutic response was defined as $50 \%$ or more reduction of HAM-D score by 6 weeks after initiation of antidepressant treatment.

Clinical data of depressant patients including age, gender, HAM-D score, antidepressant, family history, onset age, number of episode, and duration of current episode were collected for each individual. Healthy individuals without known past medical or psychiatric history or family history of MDD were included as controls. This study was approved by Samsung Medical Center Institutional Review Board. Informed consent was obtained from all participants.

Peripheral blood specimens were obtained from patients with MDD at baseline and at 6 weeks after 
initiation of antidepressant treatment. Patients were categorized into four groups according to antidepressant type used and treatment responsiveness: SSRIs responder, SSRIs nonresponder, mirtazapine responder, and mirtazapine nonresponder. For marker prioritization, we prepared pooled plasma by pooling equal amounts of plasma specimen from five individuals for each group. To investigate whether proteins detected in pooled plasma were detectable in each plasma, we used these 45 specimens individually. For protein quantitation, we used additional 166 plasma specimens at baseline and at 6 weeks after initiation of either SSRIs or mirtazapine treatment from 78 MDD patients and 10 healthy controls (Fig. 1).

\section{Materials}

NuPAGE gels $(4 \sim 12 \%)$ were acquired from Invitrogen and PIERCE (Rockford, IL, USA). Sequencing-grade modified trypsin was purchased from Promega (Madison, WI, USA). Acetonitrile (ACN; MS grade), water

\section{MIDID biomarker development}

\begin{tabular}{|l}
\hline Marker prioritization \\
\hline Specimens \\
$\cdot N=25$, pooled plasma; individual plasma \\
$>$ Analytical method \\
- Retrieved proteins: $111 \rightarrow 33$ \\
: Enzyme digestion optimization of plasma sample \\
- 3 MRM transitions per peptide \\
- Instruments : QTRAP 5500 with nano LC (Sciex) \\
$>$ Target selection \\
: RT alignment of 3 transitions \\
- Peptide uniqueness \\
SN $>8$
\end{tabular}

\section{Protein quantitation}

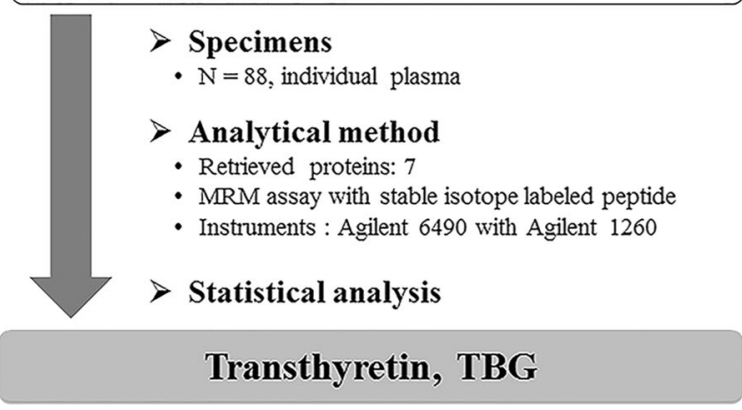

Fig. 1 Overall scheme of proteomic analysis. Plasma specimens were collected before and at 6 weeks after antidepressant treatment in each patient group and healthy individuals. MRM multiple reaction monitoring, MS mass spectrometry, $N$ number of patients, $R T$ retention time, S/N signal-to-noise ratio, TBG thyroxine-binding globulin
(MS grade), and formic acid (FA; ACS regent grade) were acquired from Aldrich (Milwaukee, WI, USA). Seven isotope-labeled peptides were synthesized as internal standards for MRM assay (AnyGen Co., Gwangju, Korea): TEDTIFL*R, VANYVDWI*NDR, ITLPDFTGDL*R, ELLESYI*DGR, VSLATV*DK, NALALFVLP*K, and AADDTWEP*FASGK for alpha-1-acid glycoprotein 1 (AGP1), hepatocyte growth factor activator (HGFA), lipopolysaccharide-binding protein (LBP), prothrombin, selenoprotein $\mathrm{P}(\mathrm{SeP})$, thyroxine-binding globulin (TBG), and transthyretin, respectively. " represents amino acid labeled with ${ }^{13} \mathrm{C}^{15} \mathrm{~N}$ heavy isotope.

\section{Marker surrogate selection}

We searched proteins that were either related to depressive disorders or located on antidepressant action sites or metabolic pathways in previous individual studies and meta-analysis. In addition to protein markers, genetic markers, DNA, and mRNA were also selected. We manually reviewed them and obtained proteins encoded by genes as well as proteins described in previous literatures. Among selected proteins, we gave priorities to proteins present in serum or plasma based on public databases including Healthy Human Individuals Integrated Plasma Proteome Database and Sys-Body Fluid database as they were studied much more in literatures. Finally, a total of 111 proteins were selected for MRM-based marker prioritization (Additional file 1: Table S1).

\section{Sample preparation}

For marker prioritization, $50 \mu \mathrm{L}$ of plasma was resolved on $4 \sim 12 \%$ NuPAGE gel which was cut into 10 bands and subjected to in-gel tryptic digestion prior to MRM analysis. In-gel digestion was achieved at a 50:1 ratio for $16 \mathrm{~h}$ at $37^{\circ} \mathrm{C}$. Tryptic digests were recovered by extraction with $50 \% \mathrm{ACN} / 0.1 \% \mathrm{FA}$ and purified using an OMIX C-18 tip (Agilent, Technologies, Santa Clara, CA, USA).

For protein quantitation, $1 \mu \mathrm{L}$ of plasma was mixed with $40 \mu \mathrm{L}$ of $10 \mathrm{mM}$ of dithiothreitol and incubated at $60{ }^{\circ} \mathrm{C}$ for $45 \mathrm{~min}$ for protein reduction. Next, $5 \mathrm{mM}$ iodoacetamide was added. Samples were incubated at room temperature for $30 \mathrm{~min}$ in the dark to induce alkylation followed by digestion with trypsin (1:50) overnight at $37^{\circ} \mathrm{C}$, after which digested samples were dried using a centrifugal evaporator. Each tryptic digest sample was spiked with stable isotope labeled peptide. Samples were dried and reconstituted with $20 \mu \mathrm{L}$ of $0.1 \%$ FA in water.

\section{MRM-based marker prioritization}

We generated MRM transitions using MRMPilot ${ }^{\mathrm{TM}}$ v2.0 (AB Sciex, Framingham, MA, USA) against 111 proteins selected by literature review. We then monitored these 
MRM methods using pooled plasma. We performed MRM analysis using a QTRAP 5500 hybrid triple quadrupole/linear ion trap mass spectrometer ( $A B$ Sciex) equipped with a nano-electrospray ion source. MRM mode setting was as follows: curtain gas and spray gas at 20 and 25 psi, respectively; collision gas set on high level; and declustering potential set at $100 \mathrm{~V}$. Among 111 proteins, 33 proteins showed signal-to-noise ratio $(\mathrm{S} / \mathrm{N})$ above 8 in pooled plasma specimen. For these 33 proteins, we performed MRM analysis using individual plasma specimens to select marker candidates for protein quantitation using stable isotope labeled peptide. The MRM method was identical to that was used for protein measurement of pooled plasma.

\section{MRM-based protein quantitation}

Through marker prioritization, seven proteins were detectable $(\mathrm{S} / \mathrm{N}>8)$ in individual plasma. For these seven proteins, we performed protein quantitation using stable isotope labeled peptide. Each tryptic digest sample was spiked with stable isotope labeled peptide. Samples were dried and reconstituted with $20 \mu \mathrm{L}$ of $0.1 \%$ FA in water. MRM analysis was performed using Agilent 6490 Triple Quadrupole mass spectrometer equipped with Agilent 1260 Infinity LC system (Agilent Technologies Inc., Table 1). Tryptic peptides were loaded onto a reversed phase analytical column $(150 \mathrm{~mm} \times 0.2 \mathrm{~mm}$ i.d., Agilent ZORBAX Eclipse Plus, $1.6 \mu \mathrm{m}$ particle size) that was maintained at a column temperature of $40{ }^{\circ} \mathrm{C}$. Sample separations were achieved using mobile phase A consisting of $0.05 \% \mathrm{FA}$ and $0.2 \%$ methanol in water and mobile phase B consisting of $0.05 \% \mathrm{FA}$ and $0.2 \%$ methanol in $\mathrm{ACN}$. The gradient method was composed of multiple linear gradients as follows (time, $\% \mathrm{~B}$, flow rate): $3 \mathrm{~min}$, $2 \% \mathrm{~B}, 0.25 \mathrm{~mL} / \mathrm{min} ; 43 \mathrm{~min}, 30 \% \mathrm{~B}, 0.25 \mathrm{~mL} / \mathrm{min} ; 47 \mathrm{~min}$, 90\% B, $0.27 \mathrm{~mL} / \mathrm{min}$; $53.1 \mathrm{~min}, 1 \%$ B, $0.25 \mathrm{~mL} / \mathrm{min}$. Separated peptides were ionized using positive electrospray ionization: $3500 \mathrm{~V}$ capillary voltage, $150 \mathrm{~V}$ (high pressure
$\mathrm{RF}$ ) and $60 \mathrm{~V}$ nozzle voltage (low pressure RF), a sheath gas flow of $11 \mathrm{~L} / \mathrm{min}$ at a temperature of $200{ }^{\circ} \mathrm{C}$, a drying gas flow rate of $16 \mathrm{~L} / \mathrm{min}$ at a temperature of $150{ }^{\circ} \mathrm{C}$, and 30 psi nebulizer gas flow.

\section{Statistical analysis}

To identify proteins differentially expressed between MDD patients and healthy individuals and between responders and nonresponders at baseline, we performed Fisher's exact test for categorical variables and t-test or Mann-Whitney U test for continuous variables. Comparisons between patients at baseline and at 6 weeks after initiation of antidepressants in total and subset of patients were performed using Wilcoxon signed rank test or paired t-test. Each comparison was independently performed for SSRIs and mirtazapine groups. Proteins and clinical variables with univariate $p$-values less than 0.200 were included in multivariate analysis using partial Spearman correlation analysis. P-value of less than 0.050 was regarded as statistically significant. SAS version 9.3 (SAS Institute, Cary, NC, USA) was used for all statistical analyses.

\section{Results}

\section{Patient characteristics and protein quantitation}

Clinical and demographic characteristics of MDD patients at baseline and healthy individuals are summarized in Table 2. Age, gender, HAM-D score, onset age, number of episode, duration of current episode, and antidepressant used in study population were investigated. Overall, SSRIs- or mirtazapine-treated patients and healthy individuals and MDD patients showed no statistically significant differences. Responders and nonresponders did not differ in any variables at baseline. Among 111 proteins selected by literature review, 33 proteins showed $\mathrm{S} / \mathrm{N}$ ratio above 8 in pooled plasma specimen. Among these 33 proteins, seven proteins (AGP1, HGFA, LBP, prothrombin, SeP, TBG, and transthyretin)

Table 1 Proteins for quantitative analysis using stable isotope labeled peptides

\begin{tabular}{|c|c|c|c|c|c|c|c|c|}
\hline \multirow[t]{2}{*}{ Protein full name } & \multirow[t]{2}{*}{ Short name } & \multirow[t]{2}{*}{ Peptide sequence } & \multirow[t]{2}{*}{ Targetion } & \multicolumn{2}{|c|}{ Intact } & \multicolumn{2}{|l|}{ IS } & \multirow[t]{2}{*}{ CE } \\
\hline & & & & Q1 & Q3 & Q1 & Q3 & \\
\hline Alpha-1-acid glycoprotein 1 & AGP1 & TEDTIFL*R & $+2 y 6$ & 497.8 & 764.4 & 501.3 & 771.4 & 16 \\
\hline Hepatocyte growth factor activator & HGFA & VANYVDWI*NDR & $+2 y 7$ & 682.8 & 917.4 & 686.3 & 924.5 & 22 \\
\hline Lipopolysaccharide-binding protein & LBP & ITLPDFTGDL*R & $+2 \mathrm{y} 8$ & 624.3 & 920.4 & 627.8 & 927.5 & 20 \\
\hline Prothrombin & Prothrombin & ELLESYI*DGR & $+2 \mathrm{y} 6$ & 597.8 & 710.3 & 601.3 & 717.4 & 19 \\
\hline Selenoprotein P & $\mathrm{SeP}$ & VSLATV*DK & $+2 \mathrm{y} 6$ & 416.7 & 646.4 & 419.7 & 652.4 & 10 \\
\hline Thyroxine-binding globulin & TBG & NALALFVLP*K & $+2 y 7$ & 543.3 & 787.5 & 546.3 & 793.5 & 13 \\
\hline Transthyretin & Transthyretin & AADDTWEP*FASGK & $+2 y 6$ & 697.8 & 606.3 & 700.8 & 612.3 & 26 \\
\hline
\end{tabular}

CE collision energy, IS internal standard 
Table 2 Clinical characteristics of major depressive patients $(n=78)$ at baseline and healthy controls $(n=10)$

\begin{tabular}{|c|c|c|c|c|c|c|}
\hline \multirow[t]{2}{*}{ Characteristics } & \multirow[t]{2}{*}{ Control } & \multicolumn{2}{|l|}{ SSRIs } & \multicolumn{2}{|c|}{ Mirtazapine } & \multirow[t]{2}{*}{$\mathbf{P}$} \\
\hline & & $\mathbf{R}$ & NR & $\mathbf{R}$ & NR & \\
\hline $\mathrm{N}$ & 10 & 19 & 16 & 22 & 21 & \\
\hline Age, mean $\pm S D$, year & $67.4 \pm 6.7$ & $65.9 \pm 12.3$ & $62.4 \pm 10.2$ & $66.4 \pm 8.8$ & $66.8 \pm 9.4$ & 0.884 \\
\hline Gender, M:F, n & $3: 7$ & $6: 13$ & $4: 12$ & $6: 16$ & $6: 15$ & 0.996 \\
\hline HAM-D score, mean \pm SD & & $19.0 \pm 3.11$ & $20.6 \pm 2.76$ & $18.2 \pm 2.64$ & $20.2 \pm 3.79$ & 0.320 \\
\hline Onset age, mean $\pm S D$, year & & $56.4 \pm 14.2$ & $57.6 \pm 9.66$ & $56.5 \pm 15.6$ & $55.1 \pm 14.5$ & 0.573 \\
\hline No. of episode, mean $\pm S D$ & & $2.58 \pm 1.92$ & $1.75 \pm 0.86$ & $2.64 \pm 2.06$ & $3.33 \pm 2.83$ & 0.376 \\
\hline $\begin{array}{l}\text { Duration of current episode, } \\
\text { mean } \pm S D, m\end{array}$ & & $4.21 \pm 3.60$ & $9.56 \pm 7.89$ & $3.86 \pm 3.12$ & $7.19 \pm 6.59$ & 0.105 \\
\hline Antidepressant used, n (\%) & & & & & & 0.956 \\
\hline Escitalopram & & $2(10.5)$ & $1(6.3)$ & & & \\
\hline Fluoxetine & & $8(42.1)$ & $9(56.3)$ & & & \\
\hline Paroxetine & & $5(26.3)$ & $3(18.8)$ & & & \\
\hline Sertraline & & $4(21.1)$ & $3(18.8)$ & & & \\
\hline Mirtazapine & & & & 22 & 21 & \\
\hline
\end{tabular}

HAM-D Hamilton Depression Rating Scale, NR nonresponders; $R$ responder; SD standard deviation, SSR/s selective serotonin reuptake inhibitors

showed $\mathrm{S} / \mathrm{N}$ ratio above 8 in individual plasma specimens. For these seven proteins, we performed quantitative analysis using stable isotope labeled peptide in 166 plasma specimens from 78 MDD patients and 10 healthy individuals and compared protein expressions for the following groups: patients vs. controls, responders vs. nonresponders, and at baseline vs. at 6 weeks after treatment.

\section{Differentially expressed proteins between MDD patients and controls}

After comparison between patients at baseline and controls, transthyretin showed lower concentration in MDD patients than that in controls (mean, $6338 \mathrm{vs} .7718 \mathrm{fmol} /$ $\mu \mathrm{L}$, uni- $\mathrm{P}=0.026$, Table 3 and Fig. $2 \mathrm{a}$ ). This statistical significance was maintained after adjusting for age and gender (multi-P = 0.038). Although AGP1 concentration was also lower in MDD patients than that in controls, such difference did not reach statistical significance (7874 vs. $9448 \mathrm{fmol} / \mu \mathrm{L}$, uni-P $=0.116$ ).

\section{Plasma protein concentrations in MDD patients treated with SSRIs}

In patients treated with SSRIs, the concentrations of HGFA and LBP were numerically different between responders and nonresponders at baseline (5.44 vs. $4.00 \mathrm{fmol} / \mu \mathrm{L}$, uni-P $=0.141$, multi-P $=0.193$ for $\mathrm{HGFA}$; 28.8 vs. $33.6 \mathrm{fmol} / \mu \mathrm{L}$, uni-P $=0.362$, multi- $\mathrm{P}=0.053$ for LBP; Table 4 and Fig. 2b). TBG levels were increased in responders after SSRI treatment (118 vs. $129 \mathrm{fmol} / \mu \mathrm{L}$, uni-P $=0.090)$. However, these differences according to responsiveness to SSRIs and changes according to SSRIs
Table 3 Plasma protein concentrations ( $\mathrm{fmol} / \mu \mathrm{L}$ ) between major depressive patients at baseline and healthy controls

\begin{tabular}{lllll}
\hline Protein & \multicolumn{2}{l}{ Mean \pm SD } & Uni-P & Multi-Pa \\
\cline { 2 - 3 } & Control & MDD & & \\
\hline N & 10 & 78 & & \\
AGP1 & $9448 \pm 3091$ & $7874 \pm 3063$ & 0.116 & 0.078 \\
HGFA & $4.71 \pm 1.39$ & $4.43 \pm 2.33$ & 0.354 & 0.422 \\
LBP & $37.2 \pm 14.6$ & $30.9 \pm 14.4$ & 0.209 & 0.200 \\
Prothrombin & $1463 \pm 323$ & $1480 \pm 327$ & 0.870 & 0.967 \\
SeP & $162 \pm 56.9$ & $144 \pm 39.6$ & 0.660 & 0.543 \\
TBG & $117 \pm 15.5$ & $119 \pm 32.3$ & 0.880 & 0.898 \\
Transthyretin & $7718 \pm 1870$ & $6338 \pm 1801$ & 0.026 & 0.038 \\
\hline
\end{tabular}

$M D D$ major depressive disorder, $S D$ standard deviation

a Multivariable P-value from partial Spearman correlation analysis including age and gender

treatment of plasma protein did not reach statistical significance.

\section{Plasma protein concentrations in MDD patients treated with mirtazapine}

In patients treated with mirtazapine, although plasma protein concentration was higher in responders than that in nonresponders for HGFA (4.48 vs. $3.79 \mathrm{fmol} / \mu \mathrm{L}$, uni-P $=0.191$ ) and lower in responders for prothrombin ( 1450 vs. $1528 \mathrm{fmol} / \mu \mathrm{L}$, uni-P $=0.057$ ) at baseline, these differences did not show statistical significance (Table 5 and Fig. 2c). 
In analysis for changes according to mirtazapine treatment, TBG was increased after mirtazapine treatment in responders (120 vs. $139 \mathrm{fmol} / \mu \mathrm{L}$, uni-P=0.007). On the other hand, TBG did not show statistically significant changes according to mirtazapine treatment in nonresponders.

\section{Discussion}

In this study, we performed MRM-based proteomic analysis using peripheral blood specimens at baseline and at 6 weeks after antidepressant treatment in MDD patients and from healthy individuals. We also quantified proteins using stable isotope labeled peptide. We identified a difference in plasma transthyretin concentration between MDD patients and healthy individuals, and a change in plasma TBG concentration related to mirtazapine treatment.

The diagnosis of MDD is primarily based on clinical features, not objective biomarkers. Biomarkers of diagnosis are potential candidates for disease monitoring. Our study showed lower transthyretin level in MDD patients than that in healthy individuals. Transthyretin is a carrier protein which transports thyroxin (T4) and retinol in plasma and CSF [31]. It has been reported that transthyretin is associated with neurodegenerative disorders and psychiatric condition including major depressive disorder [31]. Transthyretin level has been found to be low in CSF from patients with Alzheimer's Disease [3133]. Correlation between plasma transthyretin level and severity and progression of Alzheimer's disease has also been reported [34]. Previous study has also reported that CSF transthyretin level is lower in depressive patients compared to that in healthy controls $[35,36]$. Serum transthyretin level is also lower in patients with poststroke depression than that in patients without poststroke depression [37]. In preclinical studies using animal model of depression, administration of sodium butyrate, a histone deacetylase inhibitor with antidepressant-like effect, has resulted upregulation of transthyretin RNA level [38, 39]. Low plasma transthyretin level in MDD patients in our study could be meaningful in the aspect of that this is the first demonstration using plasma from MDD patients. Although conflicting findings have been reported in preclinical studies [40] and whether transthyretin alteration is a cause or consequence of MDD remains unclear, it has been suggested that low transthyretin level can lower thyroid hormone availability which may lead to depression [35, 39].

In analysis for identifying proteins whose levels are changed after antidepressant treatment, TBG level was found to be elevated after mirtazapine treatment only in responders. TBG has not been measured in MDD yet. Its changes in response to antidepressant treatment has not been investigated in previous studies either. Only one study has evaluated TBG as a predictor of perinatal syndromal depression based on relationship between hypothalamic-pituitary-thyroid axis abnormality and pregnancy-related depression [41]. TBG is one of the major thyroid-hormone binding proteins, along with transthyretin and albumin. In the present study, TBG level was increased in responders after treatment with SSRIs (uni-P $=0.090$ ) and transthyretin level was increased in responders after treatment with mirtazapine (uni- $\mathrm{P}=0.095$ ). Although these increases did not show statistical significance, they were in line with the difference of transthyretin levels between MDD patients and controls and changes of TBG levels in responders to mirtazapine. These findings suggest that alterations and changes of transportation of thyroid hormones can mediate the effect of antidepressants and clinical manifestation of MDD. These findings have not been reported in previous studies. They need to be confirmed by further studies.

When compared between responders and nonresponders to both SSRIs and mirtazapine, HGFA showed higher concentrations in responders. HGFA is involved in the HGF-Met pathway correlated in tissue protection, regeneration, and anti-fibrosis/inflammation [42]. With regard to MDD, it was suggested that the HGFA concentration correlated with severity and symptoms of depression in previous studies $[43,44]$. HGFA as a marker that predicts treatment response should be demonstrated further analysis because the correlation between HGFA concentration and treatment responsiveness was not statistically significant in our study.

We performed proteomic analysis using pre- and post-plasma specimens after SSRIs and mirtazapine treatment from MDD patients and healthy individuals. Our results showed alterations and changes of plasma proteins including transthyretin and TBG. These

\footnotetext{
(See figure on next page.)

Fig. 2 Plasma levels of thyroxine-binding globulin (TBG) and transthyretin in healthy controls and major depressive disorder (MDD) patients treated with either selective serotonin reuptake inhibitors (SSRIs) or mirtazapine. a Comparison between healthy individuals and patients with MDD. Transthyretin was higher in controls than that in MDD patients. b Plasma protein levels in MDD patients treated with SSRIs. TBG levels were increased in responders after SSRIs treatment. However, the difference did not reach statistical significances. c Plasma protein levels in MDD patients treated with mirtazapine. TBG level was increased after mirtazapine treatment. Transthyretin levels tended to be lower in responders. However, this difference did not reach the statistical significance. NR, nonresponder; $R$, responder
} 

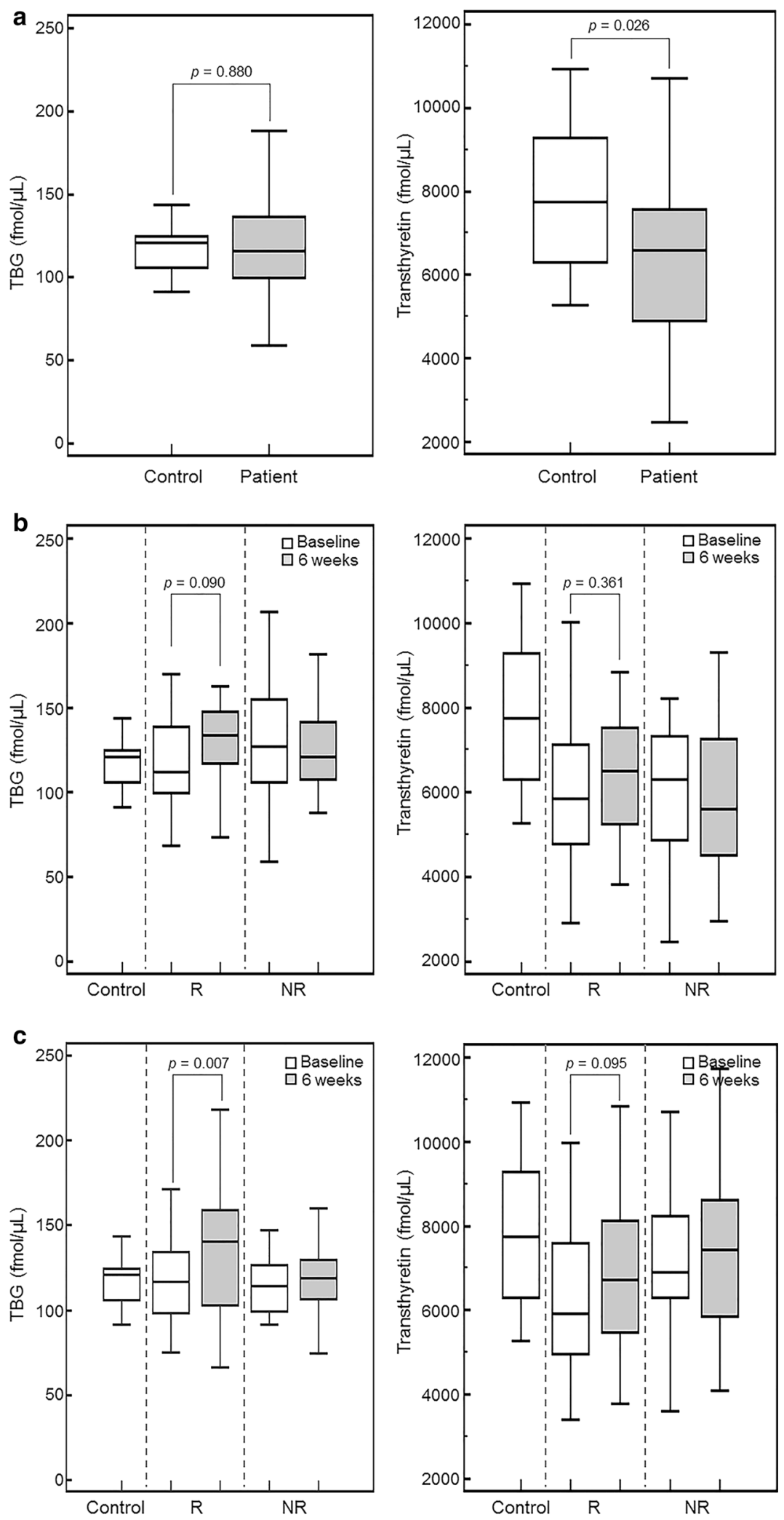
Table 4 Plasma protein concentrations $(\mathrm{fmol} / \mu \mathrm{L})$ at baseline and at 6 weeks after SSRIs treatment

\begin{tabular}{|c|c|c|c|c|c|c|c|c|}
\hline \multirow[t]{3}{*}{ Protein } & \multicolumn{3}{|l|}{ Responder } & \multicolumn{3}{|c|}{ Nonresponder } & \multicolumn{2}{|c|}{ Responsiveness } \\
\hline & \multicolumn{2}{|l|}{ Mean $\pm S D$} & \multirow[t]{2}{*}{ Uni-Pa } & \multicolumn{2}{|l|}{ Mean \pm SD } & \multirow[t]{2}{*}{ Uni-Pa } & \multirow[t]{2}{*}{ Uni-P } & \multirow[t]{2}{*}{ Multi-Pc } \\
\hline & At baseline & At 6 week & & At baseline & At 6 week & & & \\
\hline$N$ & 19 & & & 16 & & & & \\
\hline AGP1 & $8325 \pm 2672$ & $7916 \pm 2084$ & 0.455 & $8014 \pm 3334$ & $7888 \pm 2856$ & 0.433 & 0.540 & 0.954 \\
\hline HGFA & $5.44 \pm 3.60$ & $4.50 \pm 1.64$ & 0.374 & $4.00 \pm 1.55$ & $4.01 \pm 1.53$ & 0.968 & 0.141 & 0.193 \\
\hline LBP & $28.8 \pm 13.2$ & $32.0 \pm 9.58$ & 0.290 & $33.6 \pm 17.6$ & $30.0 \pm 9.54$ & 0.706 & 0.362 & 0.053 \\
\hline Prothrombin & $1485 \pm 294$ & $1499 \pm 172$ & 0.728 & $1450 \pm 316$ & $1405 \pm 325$ & 0.744 & 0.733 & 0.294 \\
\hline SeP & $137 \pm 37.1$ & $148 \pm 16.5$ & 0.237 & $129 \pm 36.9$ & $122 \pm 38.2$ & 0.464 & 0.417 & 0.465 \\
\hline TBG & $118 \pm 27.9$ & $129 \pm 24.9$ & 0.090 & $128 \pm 36.9$ & $124 \pm 24.9$ & 0.336 & 0.354 & 0.370 \\
\hline Transthyretin & $6105 \pm 1689$ & $6448 \pm 1444$ & 0.361 & $6016 \pm 1681$ & $5864 \pm 1867$ & 0.585 & 0.876 & 0.351 \\
\hline
\end{tabular}

HAM-D Hamilton Depression Rating Scale, SD standard deviation, SSRIs selective serotonin reuptake inhibitors

a P-value from Wilcoxon signed rank test or paired T-test between at baseline and at 6 weeks in each response group

b P-value from Mann-Whitney test or T-test between responders and nonresponders at baseline

c Multivariable P-value from partial Spearman correlation analysis including clinical variables with $\mathrm{P}<0.020$ (HAM-D score at baseline, number of episode, and duration of current episode)

Table 5 Plasma protein concentrations $(\mathrm{fmol} / \mu \mathrm{L})$ at baseline and at 6 weeks after mirtazapine treatment

\begin{tabular}{|c|c|c|c|c|c|c|c|c|}
\hline \multirow[t]{3}{*}{ Protein } & \multicolumn{3}{|l|}{ Responder } & \multicolumn{3}{|c|}{ Nonresponder } & \multicolumn{2}{|c|}{ Responsiveness } \\
\hline & \multicolumn{2}{|l|}{ Mean $\pm S D$} & \multirow[t]{2}{*}{ Uni-Pa } & \multicolumn{2}{|l|}{ Mean $\pm S D$} & \multirow[t]{2}{*}{ Uni-Pa } & \multirow[t]{2}{*}{ Uni-P } & \multirow[t]{2}{*}{ Multi-Pc } \\
\hline & At baseline & At 6 week & & At baseline & At 6 week & & & \\
\hline$N$ & 22 & & & 21 & & & & \\
\hline AGP1 & $7872 \pm 2719$ & $6967 \pm 1610$ & 0.087 & $7360 \pm 3620$ & $6460 \pm 1356$ & 0.448 & 0.280 & 0.462 \\
\hline HGFA & $4.48 \pm 1.84$ & $4.21 \pm 1.36$ & 0.449 & $3.79 \pm 1.51$ & $4.73 \pm 1.83$ & 0.015 & 0.191 & 0.270 \\
\hline LBP & $31.4 \pm 16.2$ & $33.4 \pm 12.7$ & 0.219 & $30.0 \pm 10.7$ & $30.8 \pm 9.64$ & 0.629 & 0.585 & 0.772 \\
\hline Prothrombin & $1450 \pm 284$ & $1549 \pm 383$ & 0.302 & $1528 \pm 412$ & $1486 \pm 395$ & 0.657 & 0.057 & 0.246 \\
\hline SeP & $146 \pm 26.2$ & $154 \pm 40.4$ & 0.389 & $157 \pm 51.4$ & $158 \pm 40.1$ & 0.974 & 0.397 & 0.395 \\
\hline $\mathrm{TBG}$ & $120 \pm 28.6$ & $139 \pm 38.3$ & 0.007 & $112 \pm 36.2$ & $118 \pm 22.5$ & 0.725 & 0.552 & 0.511 \\
\hline Transthyretin & $6294 \pm 1783$ & $6968 \pm 2063$ & 0.095 & $6841 \pm 2016$ & $7425 \pm 1954$ & 0.209 & 0.351 & 0.379 \\
\hline
\end{tabular}

HAM-D Hamilton Depression Rating Scale, SD standard deviation

a $\mathrm{P}$-value from Wilcoxon signed rank test or paired T-test between at baseline and at 6 weeks in each response group

b P-value from Mann-Whitney test or T-test between responders and nonresponders at baseline

c Multivariable P-value from partial Spearman correlation analysis including clinical variables with $\mathrm{P}<0.020$ (HAM-D score at baseline, and duration of current episode)

findings are meaningful because there are few studies about changes of protein expression after antidepressant treatment or differences at baseline associated with responsiveness. Our findings have some limitations. First, performed evaluation of our method to detect plasma proteins through several experimental stages. However, we did not validate our results using independent study population. Therefore, findings of this study should be considered as exploratory findings. Further validation study is required.

\section{Conclusions}

We identified proteins including transthyretin and TBG, which were altered in MDD after antidepressant treatment using proteomic analysis of plasma specimens. Our findings suggest that alteration and change in transportation of thyroid hormones can be related to the effect of antidepressants and clinical manifestation of MDD.

\section{Supplementary Information}

The online version contains supplementary material available at https://doi. org/10.1186/s12967-021-02702-y. 
Additional file 1: Table S1. 111 candidate proteins for proteomic analysis.

\section{Abbreviations}

MDD: Major depressive disorder; MRM: Multiple reaction monitoring; SSRIs: Selective serotonin reuptake inhibitors; TBG: Thyroxine-binding globulin; CSF: Cerebrospinal fluid; ECT: Electroconvulsive therapy; HAM-D: Hamilton rating scale for depression; AGP1: Alpha-1-acid glycoprotein 1; HGFA: Hepatocyte growth factor activator; LBP: Lipopolysaccharide-binding protein; SeP: Prothrombin, selenoprotein P; TBG: Thyroxine-binding globulin; S/N: Signal-to-noise ratio; T4: Thyroxin.

\section{Acknowledgements}

Not applicable.

\section{Authors' contributions}

DKK and S-YL have full access to all the data in the study and take responsibility for the integrity of the data and the accuracy of the data analysis. They equally contributed in study concept and design, acquisition of data; analysis and interpretation of data; critical revision of the manuscript for important intellectual content; and obtained funding for the study. HIW has contributed to data collection and analysis, interpretation of data, and manuscript writing. JP and S-WL have been contributed to data collection and revision of the manuscript, and carried out experimental analysis. All authors read and approved the final manuscript.

\section{Funding}

This study was supported by grants from the National Research Foundation (NRF), funded by the Korean government (MSIT), Republic of Korea (NRF-2020R1A2C2101276).

\section{Availability of data and materials}

All data in our study are available upon request.

\section{Ethics approval and consent to participate}

This study was approved by Samsung Medical Center Institutional Review Board. Informed consent was obtained from all participants.

\section{Consent for publication}

Consent to publish was obtained from all authors.

\section{Competing interests}

The authors declare that they have no competing interests.

\section{Author details}

1 'Department of Laboratory Medicine, Samsung Changwon Hospital, Sungkyunkwan University School of Medicine, Changwon, Korea. ${ }^{2}$ Samsung Biomedical Research Institute, Samsung Medical Center, Sungkyunkwan University School of Medicine, Seoul, Korea. ${ }^{3}$ SAIHST, Sungkyunkwan University School of Medicine, Samsung Medical Center, Seoul, Korea. ${ }^{4}$ Department of Psychiatry, Samsung Medical Center, Sungkyunkwan University School of Medicine, \#81 Irwon-ro, Gangnam-gu, Seoul 06351, Korea. ${ }^{5}$ Department of Laboratory Medicine and Genetics, Samsung Medical Center, Sungkyunkwan University School of Medicine, \#81 Irwon-ro, Gangnam-gu, Seoul 06351, Korea. ${ }^{6}$ Department of Clinical Pharmacology and Therapeutics, Samsung Medical Center, Sungkyunkwan University School of Medicine, Seoul, Korea.

Received: 31 August 2020 Accepted: 8 January 2021

Published online: 15 January 2021

\section{References}

1. Belmaker RH, Agam G. Major depressive disorder. N Engl J Med. 2008;358:55-68.

2. Ferrari AJ, Somerville AJ, Baxter AJ, Norman R, Patten SB, Vos T, Whiteford HA. Global variation in the prevalence and incidence of major depressive disorder: a systematic review of the epidemiological literature. Psychol Med. 2013:43:471-81.

3. Kessler RC, Berglund P, Demler O, Jin R, Merikangas KR, Walters EE. Lifetime prevalence and age-of-onset distributions of DSM-IV disorders in the National Comorbidity Survey Replication. Arch Gen Psychiatry. 2005;62:593-602.

4. aan het Rot M, Mathew SJ, Charney DS. Neurobiological mechanisms in major depressive disorder. CMAJ. 2009;180:305-13.

5. Howren MB, Lamkin DM, Suls J. Associations of depression with C-reactive protein, IL-1, and IL-6: a meta-analysis. Psychosom Med. 2009;71:171-86.

6. Vreeburg SA, Hoogendijk WJ, van Pelt J, Derijk RH, Verhagen JC, van Dyck R, Smit JH, Zitman FG, Penninx BW. Major depressive disorder and hypothalamic-pituitary-adrenal axis activity: results from a large cohort study. Arch Gen Psychiatry. 2009;66:617-26.

7. Musselman DL, Nemeroff CB. Depression and endocrine disorders: focus on the thyroid and adrenal system. Br J Psychiatry Suppl. 1996;168:123-8.

8. Schmidt PJ. Mood, depression, and reproductive hormones in the menopausal transition. Am J Med. 2005;118(Suppl 12B):54-8.

9. Kendler KS, Gardner CO, Prescott CA. Toward a comprehensive developmental model for major depression in men. Am J Psychiatry. 2006;163:115-24.

10. Redei EE, Mehta NS. The promise of biomarkers in diagnosing major depression in primary care: the present and future. Curr Psychiatry Rep. 2015;17:601.

11. Gartlehner G, Hansen RA, Morgan LC, Thaler K, Lux L, Van Noord M, Mager U, Thieda P, Gaynes BN, Wilkins T, Strobelberger M, Lloyd S, Reichenpfader $\mathrm{U}$, Lohr KN. Comparative benefits and harms of second-generation antidepressants for treating major depressive disorder: an updated metaanalysis. Ann Intern Med. 2011;155:772-85.

12. Simon GE, Perlis RH. Personalized medicine for depression: can we match patients with treatments? Am J Psychiatry. 2010;167:1445-55.

13. Jorgensen A, Krogh J, Miskowiak K, Bolwig TG, Kessing LV, Fink-Jensen A, Nordentoft M, Henriksen T, Weimann A, Poulsen HE, Jorgensen MB. Systemic oxidatively generated DNA/RNA damage in clinical depression: associations to symptom severity and response to electroconvulsive therapy. J Affect Disord. 2013;149:355-62.

14. Moylan S, Berk M, Dean OM, Samuni Y, Williams LJ, O'Neil A, Hayley AC, Pasco JA, Anderson G, Jacka FN, Maes M. Oxidative \& nitrosative stress in depression: why so much stress? Neurosci Biobehav Rev. 2014;45:46-62.

15. Ota KT, Liu RJ, Voleti B, Maldonado-Aviles JG, Duric V, Iwata M, Dutheil S, Duman C, Boikess S, Lewis DA, Stockmeier CA, DiLeone RJ, Rex C, Aghajanian GK, Duman RS. REDD1 is essential for stress-induced synaptic loss and depressive behavior. Nat Med. 2014;20:531-5.

16. Woo HI, Chun MR, Yang JS, Lim SW, Kim MJ, Kim SW, Myung WJ, Kim DK, Lee SY. Plasma amino acid profiling in major depressive disorder treated with selective serotonin reuptake inhibitors. CNS Neurosci Ther. 2015;21:417-24.

17. Taurines R, Dudley E, Grassl J, Warnke A, Gerlach M, Coogan AN, Thome J. Proteomic research in psychiatry. J Psychopharmacol. 2011;25:151-96.

18. Martins-de-Souza D, Guest PC, Harris LW, Vanattou-Saifoudine N, Webster MJ, Rahmoune H, Bahn S. Identification of proteomic signatures associated with depression and psychotic depression in post-mortem brains from major depression patients. Transl Psychiatry. 2012;2:e87.

19. Martins-de-Souza D, Guest PC, Vanattou-Saifoudine N, Rahmoune H, Bahn S. Phosphoproteomic differences in major depressive disorder postmortem brains indicate effects on synaptic function. Eur Arch Psychiatry Clin Neurosci. 2012;262:657-66.

20. Ditzen C, Tang N, Jastorff AM, Teplytska L, Yassouridis A, Maccarrone G, Uhr M, Bronisch T, Miller CA, Holsboer F, Turck CW. Cerebrospinal fluid biomarkers for major depression confirm relevance of associated pathophysiology. Neuropsychopharm. 2012;37:1013-25.

21. Wu D, Peng Y, Zhou J, Yang YT, Rao CL, Bai SJ, Zhou XY, Chen J, Liao L, Liang ZH, Yang DY, Xie P. Identification and validation of argininosuccinate synthase as a candidate urinary biomarker for major depressive disorder. Clin Chim Acta. 2015;451:142-8.

22. Bot M, Chan MK, Jansen R, Lamers F, Vogelzangs N, Steiner J, Leweke FM, Rothermundt M, Cooper J, Bahn S, Penninx BW. Serum proteomic profiling of major depressive disorder. Transl Psychiatry. 2015;5:e599.

23. Lee MY, Kim EY, Kim SH, Cho KC, Ha K, Kim KP, Ahn YM. Discovery of serum protein biomarkers in drug-free patients with major depressive disorder. Prog Neuropsychopharm Biol Psychiatry. 2016;69:60-8.

24. Stelzhammer V, Haenisch F, Chan MK, Cooper JD, Steiner J, Steeb H, Martins-de-Souza D, Rahmoune H, Guest PC, Bahn S. Proteomic changes 
in serum of first onset, antidepressant drug-naive major depression patients. Int J Neuropsychopharm. 2014;17:1599-608.

25. Xu HB, Zhang RF, Luo D, Zhou Y, Wang Y, Fang L, Li WJ, Mu J, Zhang $L$, Zhang $Y$, Xie P. Comparative proteomic analysis of plasma from major depressive patients: identification of proteins associated with lipid metabolism and immunoregulation. Int J Neuropsychopharm. 2012;15:1413-25.

26. Ren J, Zhao G, Sun $X$, Liu H, Jiang P, Chen J, Wu Z, Peng D, Fang Y, Zhang C. Identification of plasma biomarkers for distinguishing bipolar depression from major depressive disorder by iTRAQ-coupled LC-MS/MS and bioinformatics analysis. Psychoneuroendocrinology. 2017;86:17-24.

27. Ryan KM, Glaviano A, O'Donovan SM, Kolshus E, Dunne R, Kavanagh A, Jelovac A, Noone M, Tucker GM, Dunn MJ, McLoughlin DM. Electroconvulsive therapy modulates plasma pigment epithelium-derived factor in depression: a proteomics study. Transl Psychiatry. 2017;7:e1073.

28. Park DI, Dournes C, Sillaber I, Ising M, Asara JM, Webhofer C, Filiou MD, Muller MB, Turck CW. Delineation of molecular pathway activities of the chronic antidepressant treatment response suggests important roles for glutamatergic and ubiquitin-proteasome systems. Transl Psychiatry. 2017;7:e1078.

29. Chan MK, Cooper JD, Bot M, Birkenhager TK, Bergink V, Drexhage HA, Steiner J, Rothermundt M, Penninx BW, Bahn S. Blood-based immuneendocrine biomarkers of treatment response in depression. J Psychiatr Res. 2016;83:249-59.

30. Hamilton M. A rating scale for depression. J Neurol Neurosurg Psychiatry. 1960;23:56-62.

31. Castano EM, Roher AE, Esh CL, Kokjohn TA, Beach T. Comparative proteomics of cerebrospinal fluid in neuropathologically-confirmed Alzheimer's disease and non-demented elderly subjects. Neurol Res. 2006;28:155-63.

32. Fleming $C E$, Nunes $A F$, Sousa MM. Transthyretin: more than meets the eye. Prog Neurobiol. 2009;89:266-76.

33. Gloeckner SF, Meyne F, Wagner F, Heinemann U, Krasnianski A, Meissner B, Zerr I. Quantitative analysis of transthyretin, tau and amyloid-beta in patients with dementia. J Alzheimers Dis. 2008;14:17-25.

34. Velayudhan L, Killick R, Hye A, Kinsey A, Guntert A, Lynham S, Ward M, Leung R, Lourdusamy A, To AW, Powell J, Lovestone S. Plasma transthyretin as a candidate marker for Alzheimer's disease. J Alzheimers Dis. 2012;28:369-75.
35. Sullivan GM, Hatterer JA, Herbert J, Chen X, Roose SP, Attia E, Mann JJ, Marangell LB, Goetz RR, Gorman JM. Low levels of transthyretin in the CSF of depressed patients. Am J Psychiatry. 1999;156:710-5.

36. Sullivan GM, Mann JJ, Oquendo MA, Lo ES, Cooper TB, Gorman JM. Low cerebrospinal fluid transthyretin levels in depression: correlations with suicidal ideation and low serotonin function. Biol Psychiatry. 2006;60:500-6.

37. Wang L, Xu H, Ren W, Zhu L, Chang Y, Gu Y, Yan M, He J. Low serum prealbumin levels in post-stroke depression. Psychiatry Res. 2016:246:149-53.

38. Morinobu S, Fuchikami M, Yamawaki Y, Yamamoto S, Kurata A. Yamawaki $\mathrm{S}$ [Epigenetic mechanism of depression]. Seishin Shinkeigaku Zasshi. 2010;112:986-91.

39. Yamawaki Y, Fuchikami M, Morinobu S, Segawa M, Matsumoto T, Yamawaki S. Antidepressant-like effect of sodium butyrate (HDAC inhibitor) and its molecular mechanism of action in the rat hippocampus. World J Biol Psychiatry. 2012;13:458-67.

40. Lisowski P, Wieczorek M, Goscik J, Juszczak GR, Stankiewicz AM, Zwierzchowski L, Swiergiel AH. Effects of chronic stress on prefrontal cortex transcriptome in mice displaying different genetic backgrounds. J Mol Neurosci. 2013;50:33-57.

41. Pedersen C, Leserman J, Garcia N, Stansbury M, Meltzer-Brody S, Johnson $J$. Late pregnancy thyroid-binding globulin predicts perinatal depression. Psychoneuroendocrinology. 2016;65:84-93.

42. Nakamura T, Sakai K, Nakamura T, Matsumoto K. Hepatocyte growth factor twenty years on: Much more than a growth factor. J Gastroenterol Hepatol. 2011;26(Suppl 1):188-202.

43. Arnold SE, Xie SX, Leung YY, Wang LS, Kling MA, Han X, Kim EJ, Wolk DA, Bennett DA, Chen-Plotkin A, Grossman M, Hu W, Lee VM, Mackin RS, Trojanowski JQ, Wilson RS, Shaw LM. Plasma biomarkers of depressive symptoms in older adults. Transl Psychiatry. 2012;2:e65.

44. Russo AJ. Decreased serum hepatocyte growth factor (HGF) in individuals with depression correlates with severity of disease. Biomark Insights. 2010;5:63-7.

\section{Publisher's Note}

Springer Nature remains neutral with regard to jurisdictional claims in published maps and institutional affiliations.
Ready to submit your research? Choose BMC and benefit from:

- fast, convenient online submission

- thorough peer review by experienced researchers in your field

- rapid publication on acceptance

- support for research data, including large and complex data types

- gold Open Access which fosters wider collaboration and increased citations

- maximum visibility for your research: over $100 \mathrm{M}$ website views per year

At BMC, research is always in progress.

Learn more biomedcentral.com/submissions 